\title{
Numerical Simulations of Air Cavities in Inclined Plunging Jets
}

\author{
Qian Sun, ${ }^{1,2}$ Hao Yuan $\mathbb{D}^{2,3,4}$ Lei Jiang, ${ }^{5}$ Guangxiang Xu, ${ }^{1}$ and Xujin Zhang $^{2,3}$ \\ ${ }^{1}$ College of River and Ocean Engineering, Chongqing Jiaotong University, Chongqing 400074, China \\ ${ }^{2}$ Southwest Research Institute for Water Transport Engineering, Chongqing Jiaotong University, Chongqing 400016, China \\ ${ }^{3}$ Chongqing Xike Consultation Center for Water Transport Engineering, Chongqing Jiaotong University, \\ Chongqing 400016, China \\ ${ }^{4}$ Key Laboratory of Inland Waterway Regulation Engineering, Chongqing Jiaotong University, Chongqing 400074, China \\ ${ }^{5}$ State Key Laboratory of Hydraulics and Mountain River Engineering, Sichuan University, Chengdu 610065, China
}

Correspondence should be addressed to Hao Yuan; yuanhao@cqjtu.edu.cn

Received 6 July 2020; Revised 12 August 2020; Accepted 24 August 2020; Published 5 October 2020

Academic Editor: Bhabani S. Dandapat

Copyright (c) 2020 Qian Sun et al. This is an open access article distributed under the Creative Commons Attribution License, which permits unrestricted use, distribution, and reproduction in any medium, provided the original work is properly cited.

The dynamic process of circular water jets plunging into a quiescent pool was analyzed in this study based on the RNG $k \sim \varepsilon$ turbulence model and VOF method. The effects of jet velocity and inclination angles relative to horizontal on the cavity shapes and sizes were analyzed. The simulation successfully captured the formation, development, pinch-off, and disintegration phenomena of cavities. The shape of the cavity is mainly affected by the impact angle, while the impact velocity mainly affects the size of the cavity. The cavity pinch-off initially appears at a certain point in any direction for vertical jets, while the cavity in the opposite direction of flow pinch-off appears before the cavity in the direction of flow for inclined jets. Before cavity pinch-off, the maximum radial and axial sizes of the cavity generally increase with the impact velocity and the time after impingement. The axial penetration velocity of the cavity tip is approximately half of the impact velocity, which is consistent with previous research. Finally, based on the statistics of the cavity sizes, empirical formulas for predicting the maximum radial and axial sizes of the cavity were established.

\section{Introduction}

The phenomenon of air entrainment often occurs when a water jet from air plunges into a pool. This so-called air entrainment of the jet means that jets compact within the quiescent pool and form a relatively large cavity. The shape of the cavity changes rapidly over a short time. Then, the cavity pinches off and disintegrates into the upper and lower cavities and further decomposes into numerous bubbles. In real life, air entrainment is widely encountered in fish farming, wastewater treatment, dam discharges, and so on.

The physical experiment has always been the main mean of plunging jet research. Early related studies mainly focused on the liquid drop impact in a liquid pool $[1,2]$. This drop could penetrate the liquid layers for a distance and then bounce out, and the shape was similar to a crown. Some scholars focused on the impact of a water mass against a stationary pool. For example, Og̃uz et al. [3] fixed a vertical round tube above a pool and released a water body due to the sudden rupturing of a rubber membrane at the bottom of the round tube. In their study, the variations in cavity shape were captured, and numerical simulations were carried out [4]. To assess continuous jets, most research has consisted of experimental studies of jets plunging into a stationary pool (as shown in Table 1). For example, Zhu et al. [5] described the cavity characteristics of a vertical jet based on experimental pictures and theoretical analysis. Their results showed that the maximum radial size of the cavity changed with $\mathrm{Fr}_{0}^{(1 / 4)}\left(\mathrm{Fr}_{0}\right.$ is the Froude number at the exit of the nozzle), and the axial size changed with $\mathrm{Fr}_{0}^{(1 / 3)}$. Similarly, Soh et al. [6] also believed that the maximum axial size of the cavity for vertical jets varied with $\mathrm{Fr}_{0}^{(1 / 3)}$. Chanson et al. [7] mainly focused on the air entrainment characteristics after cavity disintegration, indicating that the maximum air concentration decreased exponentially with the axial distance from the impact point, and obtained an empirical 
TABLE 1: Studies on plunging jets in physical experiments.

\begin{tabular}{|c|c|c|c|}
\hline Reference & Jet type & Experimental conditions & Investigation \\
\hline $\begin{array}{l}\text { Bonetto and Lahey } \\
\text { [11] }\end{array}$ & $\begin{array}{l}\text { Vertical circular } \\
\text { jets }\end{array}$ & $D=0.0051 \mathrm{~m}$ & Air concentration in pool \\
\hline Zhu et al. [5] & $\begin{array}{l}\text { Vertical circular } \\
\text { jets }\end{array}$ & $D=0.0054 \mathrm{~m}, \mathrm{Fr}_{j}=38-86$ & $\begin{array}{c}\text { Air cavity formation and disintegration } \\
\text { characteristics }\end{array}$ \\
\hline Chanson et al. [7] & $\begin{array}{l}\text { Vertical circular } \\
\text { jets }\end{array}$ & $D=0.025,0.012$ and $0.00683 \mathrm{~m}, \mathrm{Fr}_{j}=50.41-100$ & Air concentration in pool \\
\hline Soh et al. [6] & $\begin{array}{l}\text { Vertical circular } \\
\text { jets }\end{array}$ & $D=0.0058-0.0075 \mathrm{~m}, \mathrm{Fr}_{j}=2.6-66.6$ & $\begin{array}{c}\text { Air cavity formation and disintegration } \\
\text { characteristics }\end{array}$ \\
\hline $\begin{array}{l}\text { Gómez-Ledesma } \\
\text { et al. [8] }\end{array}$ & $\begin{array}{l}\text { 2D plane inclined } \\
\text { jets }\end{array}$ & $\begin{array}{c}W_{j}=0.457 \mathrm{~m}, T_{j}=0.0028-0.0050 \mathrm{~m}, \\
\theta_{j}=44.8^{\circ}-82.9^{\circ}, \mathrm{Fr}_{j}=100-441\end{array}$ & $\begin{array}{c}\text { Air cavity formation and disintegration } \\
\text { characteristics }\end{array}$ \\
\hline Deshpande et al. [9] & $\begin{array}{l}\text { Inclined circular } \\
\text { jets }\end{array}$ & $D=0.04 \mathrm{~m}, \theta_{j}=12.5^{\circ}, \mathrm{Fr}_{j}=43$ & $\begin{array}{c}\text { Air cavity formation and disintegration } \\
\text { characteristics }\end{array}$ \\
\hline Qu et al. [10] & $\begin{array}{l}\text { Vertical circular } \\
\text { jets }\end{array}$ & $D=0.006 \mathrm{~m}, \mathrm{Fr}_{j}=4-208$ & $\begin{array}{c}\text { Air cavity formation and disintegration } \\
\text { characteristics }\end{array}$ \\
\hline Harby et al. [13] & $\begin{array}{l}\text { Vertical circular } \\
\text { jets }\end{array}$ & $D=0.004-0.014 \mathrm{~m}$ & Bubble plume characteristics \\
\hline Hassan et al. [15] & $\begin{array}{l}\text { Vertical circular } \\
\text { jets }\end{array}$ & $D=0.0078 \mathrm{~m}$ & Bubble plume characteristics \\
\hline
\end{tabular}

$D$ is the diameter of a nozzle; $\mathrm{Fr}_{j}$ is the Froude numbers, $\mathrm{Fr}_{j}=\left(V_{j}^{2} / g D\right)$ for circular jets, $\mathrm{Fr}_{j}=\left(V_{j}^{2} / g T_{j}\right)$ for plane jets, $V_{j}$ is the impact velocity, $T_{j}$ and $W_{j}$ are the jet thickness and width at impact point for plane jets, $\theta_{j}$ is the jet inclined angle relative to horizontal at the impact point.

expression for predicting the air entrainment concentration distribution in the pool. For inclined jets, Gómez-Ledesma et al. [8] conducted experimental research on a two-dimensional plunging jet into a pool translating at a constant speed. In their study, the jet thickness, speed, and angle relative to vertical were variables. In addition, the dynamic contours of the cavity were predicted based on the potential flow theory. Deshpande et al. [9] studied circular jet characteristics with shallow angles by experiments and computations. In general, the former studies mainly focused on the shape and size of the cavity $[5,6,10]$, the penetration depth of bubbles, and the air entrainment characteristics in the pool [7, 11-16]. However, there have been few studies on inclined jets, and the understanding of the dynamic characteristics of a cavity under inclined plunging jets is insufficient.

With the substantial improvements to computing performance and related numerical simulation methods, an increasing number of scholars have applied numerical methods to simulate plunging jets (as shown in Table 2). Galimov et al. [17] used a finite element model coupled with a level-set method to simulate the cavity caused by a vertical cylindrical jet and its subsequent disintegration, utilizing up to 40 million computational elements. Zidouni Kendil et al. [18] studied the dispersion characteristics of bubble plumes using mono- and polydispersed RANS models, and their results showed that the turbulence model has a minimal effect on the distribution of large bubbles but has a great effect on the coalescence and break-up of bubbles. Qu et al. [19] believed that the interface-tracking approach based on the level-set technique was better than the mixture model approach in predicting jet penetration depth and air entrainment characteristics. Khezzar et al. [20] applied the large eddy simulation (LES) method to simulate a vertical circular plunging jet, and the characteristics of the cavity caused by weakly and highly disturbed jets were compared. All the above studies were simulations of vertical circular jets. For inclined plunging jets, Brouilliot and Lubin [21] took the experiments of Gómez-Ledesma et al. [8] as a prototype and used the LES two-dimensional numerical method to simulate this process. Their results showed that the calculated values were in good agreement with the experimental results. Deshpande and Trujillo [22] simulated inclined jets at different angles with the code OpenFOAM. Their results showed that with an increasing angle relative to the horizontal direction, the volume of the cavity tended to decrease. Although there are more or fewer differences between the numerical results and the real or experimental values in simulating water-air two-phase flows under conditions of continuous aeration, the numerical simulation method is favoured by many scholars because it does not consider the scale effect, is conveniently modified and provides robust calculation results.

In summary, there have been many studies examining plunging jets, which has deepened our understanding of air entrainment and diffusion characteristics. However, previous studies have mainly focused on vertical circular jets, and there are few studies on inclined jets. Studies concerning cavity size have been mostly qualitative rather than quantitative. Therefore, based on the experiments of Qu et al. [10], this study simulates a water jet impacting a quiescent pool with different velocities and inclined angles relative to horizontal. The dynamic characteristics of the cavity shape are described, and the sizes are measured. Expressions for predicting the radial and axial sizes of the cavity are given. The research results provide new data for further understanding of the development characteristics of inclined water jet cavities. 
TABLE 2: Studies on plunging jets in simulations.

\begin{tabular}{|c|c|c|c|}
\hline Reference & Jet type & Simulated conditions & Investigation \\
\hline Qu et al. [19] & $\begin{array}{l}\text { Vertical } \\
\text { circular jets }\end{array}$ & $D=0.006 \mathrm{~m}$ & Air concentration in pool \\
\hline $\begin{array}{l}\text { Zidouni Kendil et al. } \\
{[18]}\end{array}$ & $\begin{array}{c}\text { Vertical } \\
\text { circular jets }\end{array}$ & $D=0.016 \mathrm{~m}$ & Air concentration in pool \\
\hline Ma et al. [23] & $\begin{array}{l}\text { Vertical } \\
\text { circular jets }\end{array}$ & $D=0.025 \mathrm{~m}, \mathrm{Fr}_{j}=50$ & Air concentration in pool \\
\hline $\begin{array}{l}\text { Brouilliot and Lubin } \\
{[21]}\end{array}$ & $\begin{array}{l}\text { 2D plane } \\
\text { inclined jets }\end{array}$ & $\begin{array}{c}W_{j}=0.457 \mathrm{~m}, T_{j}=0.0029-0.0038 \mathrm{~m}, \\
\theta_{j}=57.5^{\circ}-82.9^{\circ}, \mathrm{Fr}_{j}=100-388\end{array}$ & $\begin{array}{c}\text { Air cavity formation and disintegration } \\
\text { characteristics }\end{array}$ \\
\hline $\begin{array}{l}\text { Deshpande and } \\
\text { Trujillo [22] }\end{array}$ & $\begin{array}{l}\text { Inclined } \\
\text { circular jets }\end{array}$ & $\begin{array}{c}D=0.02 \text { and } 0.004 \mathrm{~m}, \theta_{\mathrm{j}}=10^{\circ}-90^{\circ} \\
\mathrm{Fr}_{j}=43-97\end{array}$ & $\begin{array}{c}\text { Air cavity formation and disintegration } \\
\text { characteristics }\end{array}$ \\
\hline Khezzar et al. [20] & $\begin{array}{c}\text { Vertical } \\
\text { circular jets }\end{array}$ & $D=0.006 \mathrm{~m}, \mathrm{Fr}_{j}=70$ and 90 & $\begin{array}{c}\text { Air cavity formation and disintegration } \\
\text { characteristics }\end{array}$ \\
\hline $\begin{array}{l}\text { Boualouache et al. } \\
\text { [24] }\end{array}$ & $\begin{array}{l}\text { Vertical } \\
\text { circular jets }\end{array}$ & $D=0.025,0.012$ and $0.00683 \mathrm{~m}, \mathrm{Fr}_{j}=72.25$ & $\begin{array}{l}\text { Air cavity formation and disintegration } \\
\text { characteristics, air concentration in pool }\end{array}$ \\
\hline
\end{tabular}

$D$ is the diameter of a nozzle; $\mathrm{Fr}_{j}$ is the Froude numbers, $\mathrm{Fr}_{j}=\left(V_{j}^{2} / g D\right)$ for circular jets, $\mathrm{Fr}_{j}=\left(V_{j}^{2} / g T_{j}\right)$ for plane jets, $V_{j}$ is the impact velocity, $T_{j}$ and $W_{j}$ are the jet thickness and width at impact point for plane jets, $\theta_{j}$ is the jet inclined angle relative to horizontal at the impact point.

\section{Mathematical Description and Numerical Modelling}

A water jet plunging into a pool is a two-phase air-water transient flow problem. The parallel, pressure-based commercial software ANSYS FLUENT (version 18.0), which has wide application in hydraulic engineering computations [25, 26], was employed as the solver of the Navier-Stokes equations in this study. The continuity equation and the momentum equation are as follows:

$$
\begin{gathered}
\frac{\partial \rho}{\partial t}+\frac{\partial \rho u_{i}}{\partial x_{i}}=0 \\
\frac{\partial \rho u_{i}}{\partial t}+\frac{\partial\left(\rho u_{i} u_{j}\right)}{\partial x_{j}}=-\frac{\partial p}{\partial x_{i}}+\frac{\partial}{\partial x_{j}}\left(2 \mu S_{i j}-\rho \overline{u_{i}^{\prime} u_{j}^{\prime}}\right),
\end{gathered}
$$

where $i$ and $j$ are indices, $x_{i}(i=1,2,3)$ represents the $i$ th component of the coordinate system, $\rho$ the flow density, $t$ the time, $p$ the pressure, $\mu$ the molecular viscosity, $u_{i}$ the velocity component, $u_{i}^{\prime}$ is the turbulent velocity component, $S_{i j}$ is the mean strain-rate tensor, and $-\rho \overline{u_{i}^{\prime} u_{j}^{\prime}}$ is the Reynolds stress.

The RNG $k \sim \mathcal{E}$ turbulence model is adopted to solve the fluid problem. The transportation equations of turbulence kinetic energy $k$ and its rate of dissipation $\varepsilon$ are as follows:

$$
\begin{aligned}
& \frac{\partial \rho k}{\partial t}+\frac{\partial\left(\rho k u_{i}\right)}{\partial x_{i}}=\frac{\partial}{\partial x_{j}}\left(\alpha_{k} \mu_{\mathrm{eff}} \frac{\partial k}{\partial x_{j}}\right)+G_{k}-\rho \varepsilon, \\
& \frac{\partial \rho \varepsilon}{\partial t}+\frac{\partial\left(\rho \varepsilon u_{i}\right)}{\partial x_{i}}=\frac{\partial}{\partial x_{j}}\left(\alpha_{\varepsilon} \mu_{\mathrm{eff}} \frac{\partial \varepsilon}{\partial x_{j}}\right)+\frac{C_{1 \varepsilon}^{*} \varepsilon}{k} G_{k}-C_{2 \varepsilon} \rho \frac{\varepsilon^{2}}{k},
\end{aligned}
$$

where $\mu_{\text {eff }}=\mu+\mu_{t}, \mu_{t}$ is the turbulence viscosity, and $G_{k}$ presents the generation of turbulence kinetic energy due to the velocity gradients. They are expressed as follows:

$$
\begin{aligned}
G_{k} & =u_{t}\left(\frac{\partial u_{i}}{\partial x_{j}}+\frac{\partial u_{j}}{\partial x_{i}}\right) \frac{\partial u_{i}}{\partial x_{j}}, \\
\mu_{t} & =\rho C_{\mu} \frac{k^{2}}{\varepsilon}, \\
C_{1 \varepsilon}^{*} & =C_{1 \varepsilon}-\frac{\eta\left(1-\left(\eta / \eta_{0}\right)\right)}{1+\beta \eta^{3}}, \\
\eta & =\frac{k}{\varepsilon} \sqrt{\left(2 E_{i j} \cdot E_{i j}\right)}, \\
E_{i j} & =\frac{1}{2}\left(\frac{\partial u_{i}}{\partial x_{j}}+\frac{\partial u_{j}}{\partial x_{i}}\right) .
\end{aligned}
$$

The constants of $k-\varepsilon$ equations are $C_{\mu}=0.0845$, $\alpha_{k}=\alpha_{\varepsilon}=1.39, C_{1 \varepsilon}=1.42, C_{2 \varepsilon}=1.68, \eta_{0}=4.38, \beta=0.012$.

The VOF method was used to track the water-air interface, which was proposed by Hirt and Nichols [27]. They defined a function $F(\alpha)$ representing the fractional volume of a cell occupied by fluid. In each cell, the sum of the volume fractions of the phases is $1 . F(\alpha)=1$ means that the cell is fully filled with $\alpha$, while $F(\alpha)=0$ indicates that the cell does not contain $\alpha$. A cell with $F(\alpha)=0$ to 1 represents that it contains a free surface. There are several VOF interfacetracking schemes in the FLUENT solver, including the firstorder and the second-order upwind schemes, the georeconstruction scheme, the compressive interface capturing scheme for arbitrary mesh, and the modified high-resolution interface capturing scheme. A detailed description of these schemes can be found in the ANSYS FLUENT theory guide [28]. In this study, the georeconstruction scheme is adopted, which is the preferred scheme when solving on mesh of poor quality. It is the most accurate scheme but is more computationally expensive than the other schemes [28].

\section{Numerical Simulation Details}

3.1. Computational Domain and Mesh Generation. The dynamic shapes of cavities for vertical circular plunging 
jets were measured in detail using high-speed photography technology by $\mathrm{Qu}$ et al. [10]. On this basis, this study simulated a plunging jet with different jet velocities and angles relative to horizontal. The geometry and calculation domains are shown in Figure 1 and the schematic of the air cavity is shown in Figure 2. The nozzle is round, with a diameter $D=6 \mathrm{~mm}$ and length $L=0.12 \mathrm{~m}(20 D)$. The degree of turbulence approaches full development at the exit of the nozzle according to Khezzar et al. [20]. After the jet flows out of the round nozzle, it moves in the air for a distance and enters a stationary square pool filled with water. The square pool is $0.3 \mathrm{~m}$ in length, and the water level inside the pool is kept constant at the height of $0.2 \mathrm{~m}$. The vertical distance from the exit of the round nozzle to the initial water surface $(S)$ is $0.1 \mathrm{~m}$. The angle between the centreline of the circular nozzle and the horizontal plane is defined as $\theta_{0}$. To ensure the jet trajectory of each case is included in the calculation domain, the relative position of the nozzle and the pool are adjusted according to the jet trajectory. The outlet is far away from the impact point to avoid the water flow influencing the cavity shape.

Considering the experimental conditions of $\mathrm{Qu}$ et al. [10], the inlet velocity $\left(V_{\text {in }}\right)$ in the numerical calculation is set at $1.5 \mathrm{~m} / \mathrm{s}, 2.0 \mathrm{~m} / \mathrm{s}$, and $2.5 \mathrm{~m} / \mathrm{s}$. To study the characteristics of the cavity under the condition of inclined jets, $\theta_{0}$ is set at $90^{\circ}, 60^{\circ}$, and $45^{\circ}$. The simulated cases are listed in Table 3, where $V_{0}$ is the exit velocity of the round nozzle (acquired from numerical simulations); $V_{j}$ is the impact velocity, $V_{j}=\sqrt{V_{0}^{2}+2 g S ;} \theta_{j}$ is the impact angle (the angle between the direction of $V_{j}$ and horizontal); $\mathrm{Fr}_{j}$ is the Froude number, $\mathrm{Fr}_{j}=\left(V_{j}^{2} / g D\right) ; \mathrm{Re}_{j}$ is the Reynolds number, $\operatorname{Re}_{j}=\left(V_{j} D / \nu\right) ; \quad \mathrm{We}_{j}$ is the Weber number, $\mathrm{We}_{j}=\left(\rho V_{j}^{2} D / \sigma\right)$; and $t_{p}$ is the pinch-off time for the cavity. $g$ is the acceleration of gravity, and $\nu, \sigma$, and $\rho$ are the kinematic viscosity, surface tension, and density of water, respectively.

The unstructured tetrahedral mesh was applied to the calculation domain, and the boundary layers were set on the wall surface of the circular nozzle and initial water surface (as shown in Figure 3). The mesh in the nozzle, the jet, and the water surface were locally densified, and the rest of the region was assigned a slightly larger mesh. To determine the effect of mesh size on the simulated results, a mesh-size analysis was considered. Table 4 lists the mesh information and simulated sizes of the cavity, in which $t$ is water jet entrance time, the initial time $(t=0 \mathrm{~ms})$ corresponds to the time of the jet impact on the pool surface.

3.2. Boundary Conditions and Simulation Strategy. The inlet was located at the top of the circular nozzle and was set as the velocity inflow boundary along the axial direction of the nozzle. The sidewall above the initial water surface of the pool was set as the free outflow boundary to ensure that the water depth in the pool remained constant. The exit of the round nozzle was the interior boundary. The no-slip wall

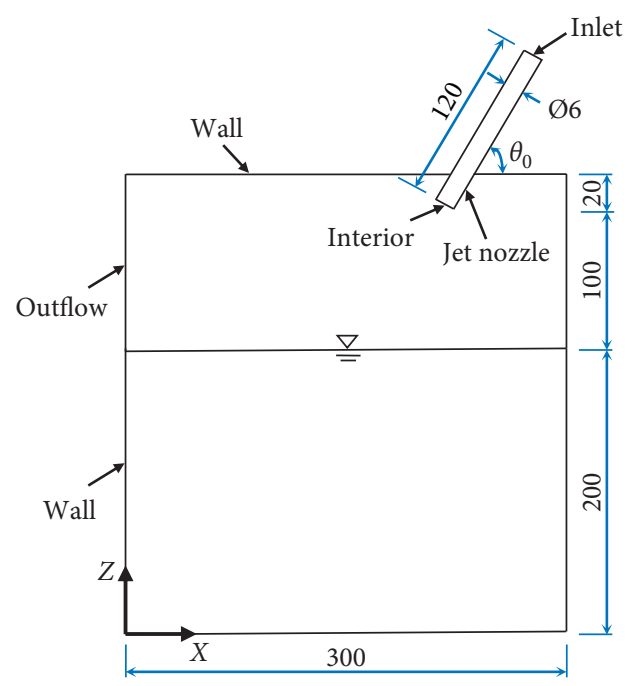

FIgURE 1: Schematic of the calculation domain and boundary conditions (unit: $\mathrm{mm}$ ).

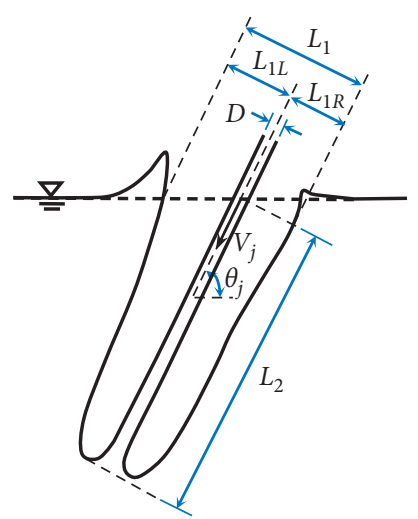

FIgURE 2: Schematic of the underwater jet and air cavity.

boundary condition was specified at the other domains for simulations.

At the initial time, the domain below the water surface was stationary water, and the domain above the surface was stationary air. A fixed time step (e.g., $2 \times 10^{-4} \mathrm{~s}$ ) was used for all simulations. The residuals were monitored to judge whether the computational model was convergent. The solution was said to have converged if the residuals were smaller than prefixed values ranging between $10^{-3}$ and $10^{-6}$. In this work, the residual values were set to $10^{-3}$ for all the variables. The simulated times were varied with $\theta_{0}$ and $V_{\text {in }}$ between $0.2 \mathrm{~s}$ and $0.25 \mathrm{~s}$.

3.3. Mesh-Size Analysis and Validation. Zhu et al. [5] used photography to monitor the cavity variation due to a vertical plunging jet and combined it with theoretical analysis, simplified the cavity into the shape shown in Figure 4, and obtained equations of the characteristic sizes: 
TABLE 3: Jet parameters for 9 cases in this study.

\begin{tabular}{|c|c|c|c|c|c|c|c|c|c|}
\hline Case & $\theta_{0}\left(^{\circ}\right)$ & $V_{\text {in }}\left(\mathrm{m} \cdot \mathrm{s}^{-1}\right)$ & $V_{0}\left(\mathrm{~m} \cdot \mathrm{s}^{-1}\right)$ & $V_{j}\left(\mathrm{~m} \cdot \mathrm{s}^{-1}\right)$ & $\theta_{j}\left({ }^{\circ}\right)$ & $\mathrm{Fr}_{j}$ & $\mathrm{Re}_{j}$ & $\mathrm{We}_{j}$ & $t_{p}(\mathrm{~ms})$ \\
\hline $\mathrm{A} 1$ & 90 & 1.5 & 1.55 & 2.09 & 90 & 74 & 12411 & 360 & 47 \\
\hline A2 & 90 & 2.0 & 2.08 & 2.51 & 90 & 107 & 14897 & 518 & 50 \\
\hline $\mathrm{A} 3$ & 90 & 2.5 & 2.59 & 2.94 & 90 & 147 & 17492 & 715 & 53 \\
\hline B1 & 60 & 1.5 & 1.53 & 2.07 & 68.5 & 73 & 12323 & 355 & 35 \\
\hline $\mathrm{B} 2$ & 60 & 2.0 & 2.05 & 2.48 & 65.8 & 105 & 14750 & 508 & 44 \\
\hline B3 & 60 & 2.5 & 2.58 & 2.94 & 64.1 & 146 & 17440 & 710 & 53 \\
\hline $\mathrm{C} 1$ & 45 & 1.5 & 1.51 & 2.06 & 58.9 & 72 & 12235 & 350 & 26 \\
\hline $\mathrm{C} 2$ & 45 & 2.0 & 2.03 & 2.47 & 54.6 & 103 & 14652 & 501 & 44 \\
\hline C3 & 45 & 2.5 & 2.57 & 2.93 & 51.9 & 146 & 17388 & 706 & 54 \\
\hline
\end{tabular}
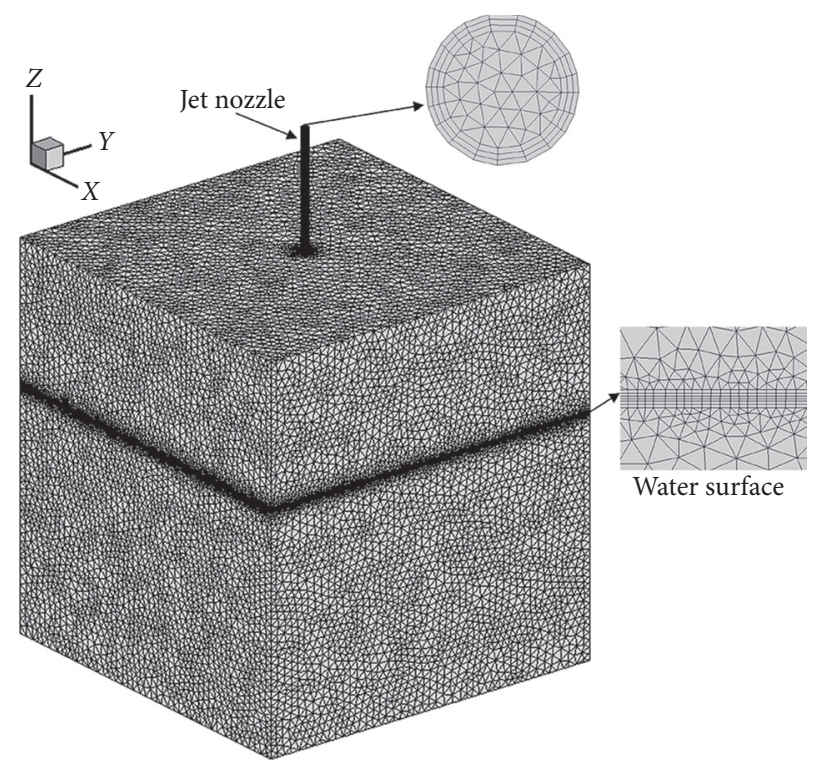

Figure 3: Scheme of mesh.

TABle 4: Mesh information and simulated sizes of the cavity $\left(\theta_{0}=90^{\circ}, V_{\text {in }}=1.5 \mathrm{~m} / \mathrm{s}\right)$.

\begin{tabular}{lcccccccc}
\hline Number & $\begin{array}{c}\text { Mesh size/ } \\
\mathrm{mm}\end{array}$ & $\begin{array}{c}\text { Number of } \\
\text { elements/Million }\end{array}$ & $\begin{array}{c}L_{1} / D \\
(t=20 \mathrm{~ms})\end{array}$ & $\begin{array}{c}L_{2} / D \\
(t=20 \mathrm{~ms})\end{array}$ & $\begin{array}{c}L_{1} / D \\
(t=40 \mathrm{~ms})\end{array}$ & $\begin{array}{c}L_{2} / D \\
(t=40 \mathrm{~ms})\end{array}$ & $\begin{array}{c}L_{1} / D \\
(t=46.67 \mathrm{~ms})\end{array}$ & $\begin{array}{c}L_{2} / D \\
(t=46.67 \mathrm{~ms})\end{array}$ \\
\hline I & 1.2 & 5.69 & 2.80 & 3.54 & 3.57 & 7.01 & 3.75 & 8.41 \\
II & 1.1 & 6.72 & 2.82 & 3.65 & 3.65 & 7.25 & 3.78 & 8.82 \\
III & 1.0 & 7.94 & 2.81 & 3.64 & 3.62 & 7.27 & 3.78 & 8.85 \\
IV & 0.9 & 9.33 & 2.83 & 3.66 & 3.65 & 7.38 & 3.79 & 8.98 \\
V & 0.8 & 10.85 & 2.84 & 3.69 & 3.67 & 7.44 & 3.81 \\
\hline
\end{tabular}

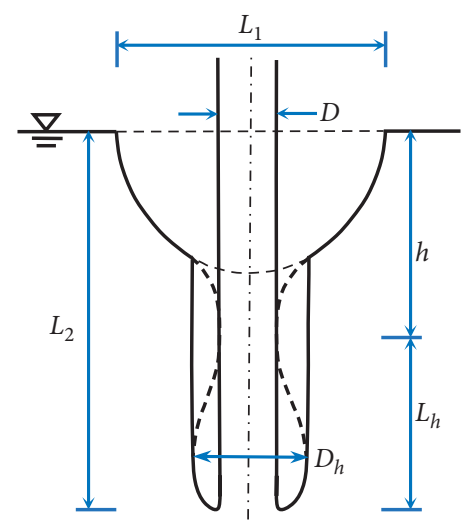

FIGURE 4: Definition of the geometric parameters of the underwater cavity of the vertical jet [5]. 


$$
\begin{aligned}
\frac{L_{1}}{D} & =2 c \mathrm{Fr}_{0}^{(1 / 4)} \\
\frac{h}{D} & =\frac{1}{4}\left(\frac{L_{1}}{D}\right)^{(2 / 3)} \mathrm{Fr}_{0}^{(1 / 3)}+2 c \mathrm{Fr}_{0}^{(1 / 4)} \\
\frac{L_{h}}{D} & =\frac{1}{2}\left(2 \frac{D_{h}}{D}\right)^{(2 / 3)} \mathrm{Fr}_{0}^{(1 / 3)} \\
\frac{D_{h}}{D} & =2.41
\end{aligned}
$$

where $D_{h}$ is the diameter of the secondary cylindrical cavity, $L_{h}$ is the length of the secondary cylindrical cavity, $h$ is the depth of the pinch-off point below the undisturbed pool surface, $\mathrm{Fr}_{0}$ is the Froude number at the nozzle exit, $\mathrm{Fr}_{0}=\left(V_{0}^{2} / g D\right)$, and $c$ is a constant equal to 0.9 .

The comparison between the computational results in different mesh and the experimental results [10] are shown in Figure 5. The simulated results of CFD could well describe the transient shape change of the cavity, but there were certain differences in size. It can be seen from Figure 5 that the axial size of the calculated cavity was slightly smaller than that of the experiments, but the radial size was quite different. The characteristic sizes of the cavity for CFD in this study, the experimental value of $\mathrm{Qu}$ et al. [10], the empirical formula of Zhu et al. [5] and the LES of Khezzar et al. [20] are listed in Table 5. It can be seen from Table 5 that the simulated results in this study are smaller than the experimental values, and the maximum relative error is $24.92 \%$ relative to the experimental value. The limited mesh resolution might explain these discrepancies. However, the existence of these discrepancies does not seriously hinder the prediction of cavity shape and size variation in this study. It can be seen from Figure 5 and Table 5 that Mesh IV and Mesh V can basically predict the shape and size changes of the cavity, and the prediction results are close. Therefore, in considering the results and computational resources comprehensively, the size in mesh IV was selected to calculate the subsequent cases.

\section{Results and Discussion}

4.1. General Characteristics of Cavity Shape. The 3D Isosurfaces of the water volume fraction $(\alpha=0.5)$ and phases in the median plane are shown in Figures 6 to 8 . The multiphase figures lie in the median plane; the blue colour indicates air and red indicates water. In all cases, the initial time ( $t=0 \mathrm{~ms}$ ) corresponds to the time of the jet impact on the pool surface. Pinch-off occurs $\left(t=t_{p}\right)$ when any sidewall of the cavity touches the surface of the jet at a point below the free water surface.

When a liquid jet plunges into a quiescent pool, the transient impact initiates the creation of a relatively large air cavity (Figures 6-8), and the cavity shape changes rapidly over a short time period. Subsequently, the cavity pinches off under the free surface and further disintegrates into bubbles. In addition, the shape of the cavity is closely related to the time after impacting, jet cross-section at the impact point, impact velocity, impact angle, viscosity of the liquid, and other factors. In this study, we mainly focus on the impact velocity, angle, and time of the water jet.

4.1.1. The Regularity of Cavity Shape Changing with Time. As shown in Figure 6, when the jet moved in the air, the air interacted with the water jet, and the surface of the jet became rough because of air entrainment. Just following the initial impact, a conical air cavity was created. The water around the cavity rose and formed a toroidal contour. The maximum rising value appeared at the junction of the cavity and water body above the water surface, which decreased with the distance from the impact point. The maximum rising value first increased and then decreased with time. The size of the cavity increased rapidly after impingement, and the axial size growth rate was greater than that of the radial cavity. Then, at a certain instant, the lower part of the cavity was pinched off by secondary water flow, thus forming two cavities. Thereafter, the upper cavity contracted towards the surface of the water, and the lower cavity moved further in the direction of the jet and further disintegrated into smaller bubbles.

Even though the water jet impacts the pool vertically $\left(\theta_{0}=90^{\circ}\right)$, the pinch-off of the cavity is not axisymmetric. The pinch-off of the cavity usually starts at a point and then expands to different directions until the cavity completely pinches off, forming the upper and lower cavities. The pinchoff times of the cavity in different cases are listed in Table 3. As we can see in Table 3, the pinch-off time increased with velocity. In addition, the pinch-off time space of $\theta_{0}=45^{\circ}$ was greater. The smaller $\theta_{0}$ was, the greater the rate of increase was.

4.1.2. Effects of Jet Inclined Angle on Cavity Shape. In nature, a jet impacting a liquid pool may not be vertical, such as a dam discharge into a plunge pool. The effects of an inclined angle on the cavity are discussed below.

When $\theta_{0}=90^{\circ}$ (cases A1-A3), the jet impacted vertically on the surface of the pool. The cavity shape was almost symmetrical about the jet centreline. However, for the inclined jet, the cavity was asymmetrical about the jet centreline. The rising value of the water level on the left (flow direction) was higher than that on the right. As we can see in Figure 7 , when $\theta_{0}=60^{\circ}$ and $V_{\text {in }}=2.0 \mathrm{~m} / \mathrm{s}$, the cavity pinches off first in the $Y$ direction near the right side ( $X$ positive direction). When $\theta_{0}=45^{\circ}$ and $V_{\text {in }}=2.0 \mathrm{~m} / \mathrm{s}$, the shape of the cavity was similar to the one when $\theta_{0}=60^{\circ}$ and $V_{\text {in }}=2.0 \mathrm{~m} / \mathrm{s}$, but the region of the right cavity along the positive $X$ direction pinches off first.

In other words, the extending direction of the cavity underwater was nearly the initial impact direction before the cavity pinch-off. The cavity shape was almost symmetrical for the vertical jet, but for the inclined jet, it was asymmetrical. In addition, the cavity in the opposite direction pinches off before the cavity in the direction of flow for inclined jets. 

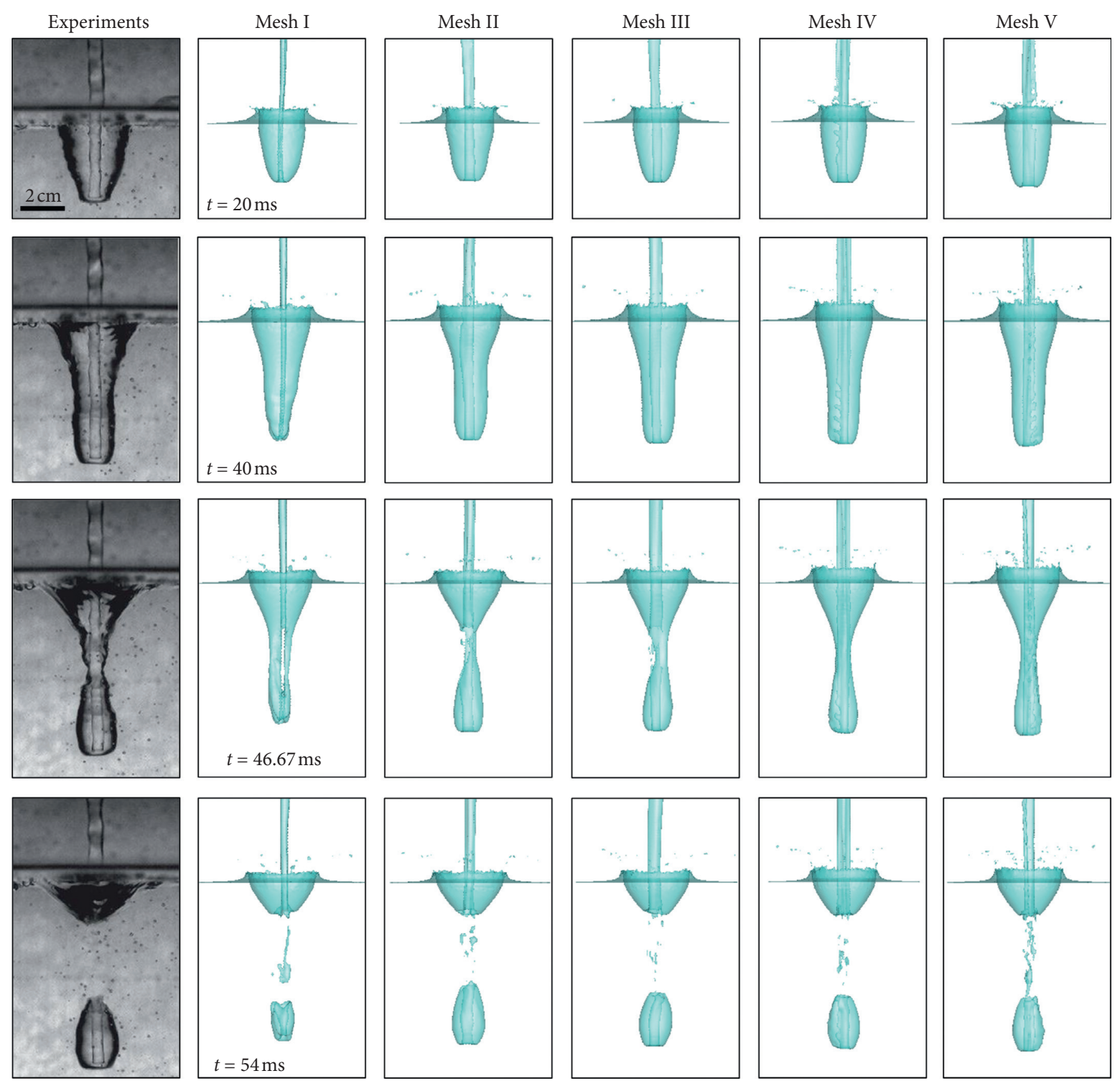

Figure 5: 3D Iso-surfaces of the water volume fraction $(\alpha=0.5)$ compared with experiments [10].

TABLE 5: Comparison of the characteristic sizes of cavities for different methods $\left(\theta_{0}=90^{\circ}, V_{\text {in }}=1.5 \mathrm{~m} / \mathrm{s}\right)$.

\begin{tabular}{lcccc}
\hline & $L_{1} / D$ & $D_{h} / D$ & $h / D$ & $L_{h} / D$ \\
\hline Qu et al. (experiment) [10] & 5.05 & 2.30 & 5.87 & 5.00 \\
Zhu et al. (empirical formula) [5] & 4.51 & 2.41 & 6.82 & 4.85 \\
Khezzar et al. (LES of highly disturbed jet) [20] & 5.50 & 2.33 & 4.42 & 10.87 \\
Khezzar et al.(LES of weakly disturbed jet) [20] & 5.16 & 1.83 & 3.92 & 5.17 \\
This study & 3.79 & 1.93 & 4.44 & 4.58 \\
Relative error & $24.92 \%$ & $16.16 \%$ & $24.39 \%$ & 9.54 \\
\hline
\end{tabular}

Relative error $=\mid$ experimental value-simulated value in this study $\mid /$ experimental value $\times 100 \%$.

4.1.3. Effects of Jet Velocities on Cavity Shape. Different velocities were set at the inlet in this study to examine the influence of velocity variation. Due to space limitations, this study only presented the cavity at three different inclined angles when $V_{\text {in }}=2.0 \mathrm{~m} / \mathrm{s}$ (Figures $6-8$ ). The velocity variation has little fluence on the shape of the cavity for the same jet inclination angle. As the velocity increased, both the axial and radial sizes increased. At the same time, the surface of the jet was rougher for smaller velocities. When $\theta_{0}=60^{\circ}$ and $V_{\text {in }}=1.5 \mathrm{~m} / \mathrm{s}$ or $2.0 \mathrm{~m} / \mathrm{s}$, the cavity pinch-off first appeared in the $Y$ direction near the right side ( $X$ positive direction), but for $V_{\text {in }}=2.5 \mathrm{~m} / \mathrm{s}$, the region of the right cavity along the positive $X$ direction experienced pinch-off first. For $\theta_{0}=45^{\circ}$, the region of the right cavity along the positive $X$ direction 

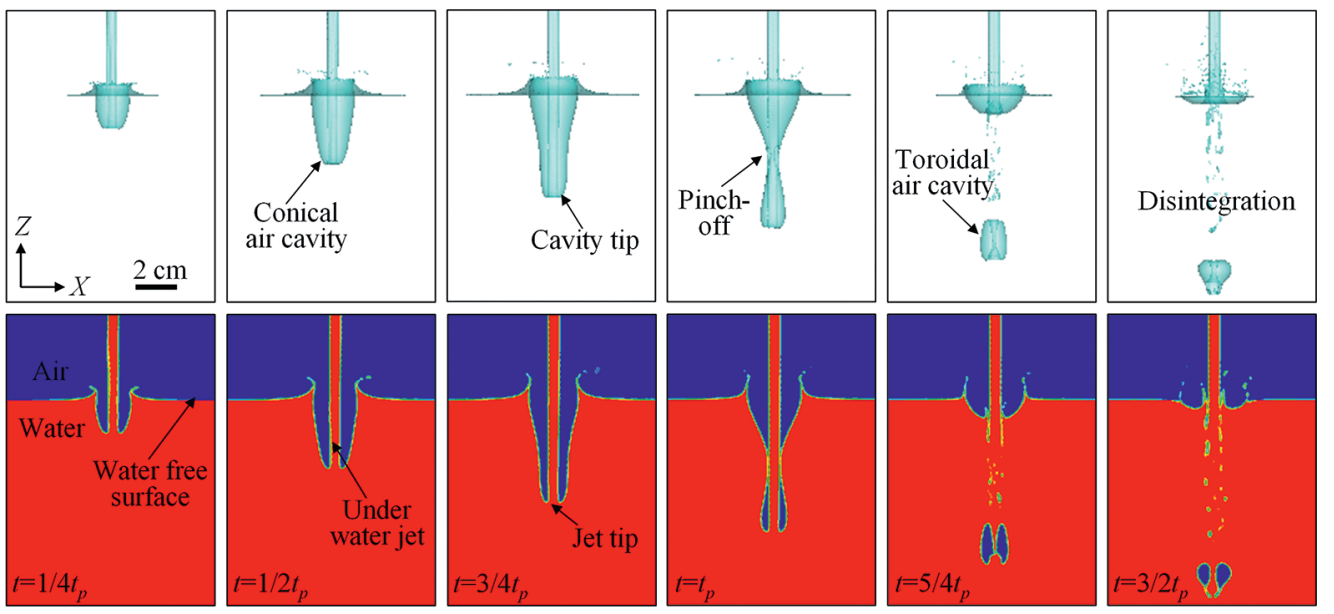

FIgURE 6: 3D Iso-surfaces of the water volume fraction $(\alpha=0.5)$ and phases in the median plane $\left(\theta_{0}=90^{\circ}, V_{\text {in }}=2.0 \mathrm{~m} / \mathrm{s}\right)$.
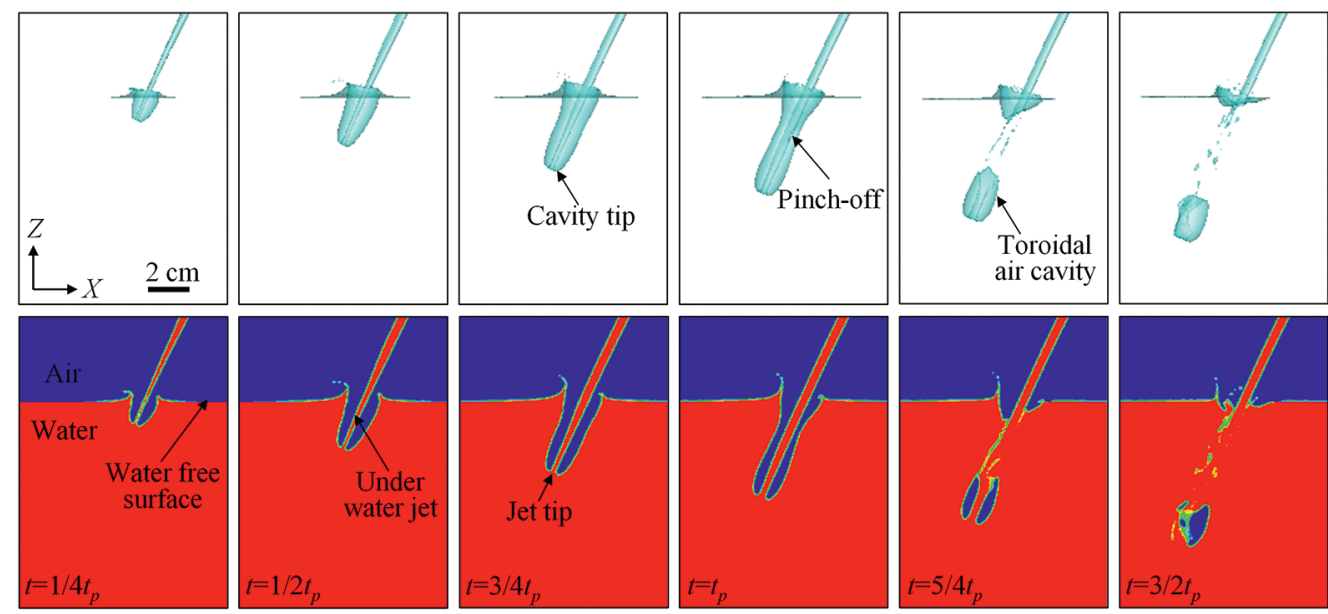

Figure 7: 3D Iso-surfaces of the water volume fraction $(\alpha=0.5)$ and phases in the median plane $\left(\theta_{0}=60^{\circ}, V_{\text {in }}=2.0 \mathrm{~m} / \mathrm{s}\right)$.
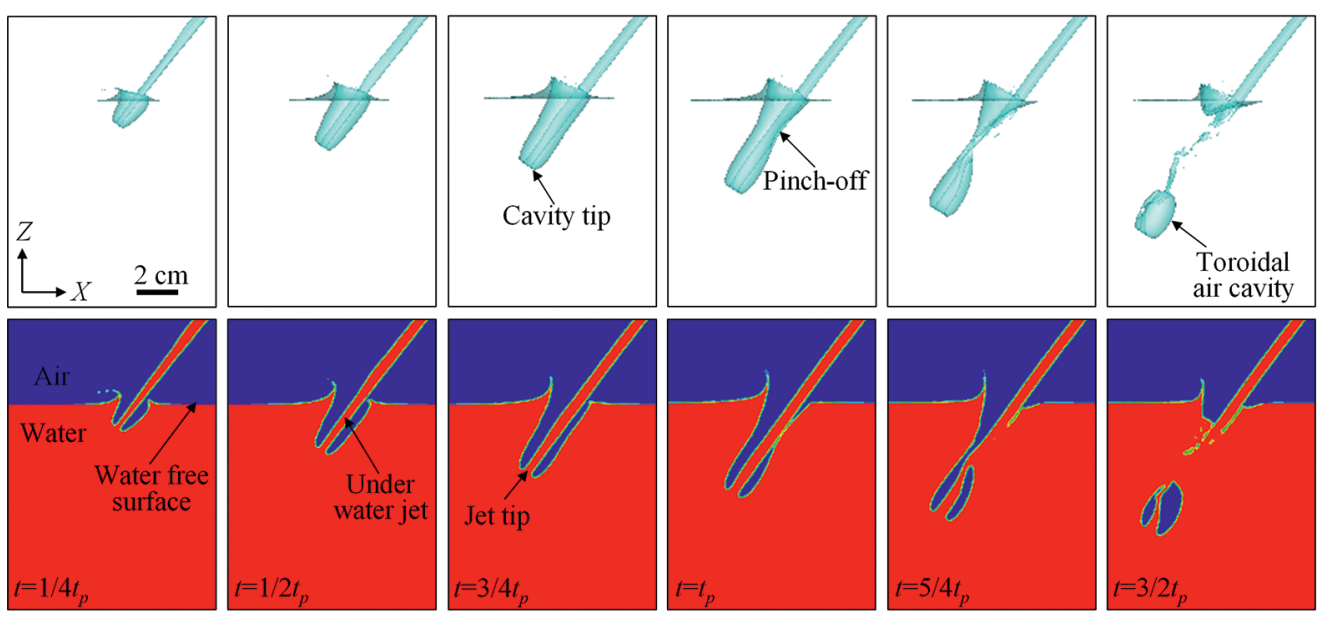

Figure 8: 3D Iso-surfaces of the water volume fraction $(\alpha=0.5)$ and phases in the median plane $\left(\theta_{0}=45^{\circ}, V_{\text {in }}=2.0 \mathrm{~m} / \mathrm{s}\right)$. 
pinched off first at each simulated velocity in this study. The pinch-off of the cavity was the result of the squeezing action of the secondary water flow. The force of the cavity was different under different conditions, so the pinch-off position was different.

4.2. Cavity Sizes. The air cavity contours were obtained by creating an Iso-surface for water concentration with a threshold value equal to $0.5(\alpha=0.5)$. The contours of the air cavity in the median plane $(Y=0.15 \mathrm{~m})$ for all cases at $t=1 /$ $4 t_{p}, 1 / 2 t_{p}, 3 / 4 t_{p}$ and $t_{p}$ are presented in Figure 9 . It should be noted that the statistics of the cavity sizes in this study were only limited to the region below the initial water surface, and the part above the initial water surface was not considered for vertical jets. For inclined jets, statistics on the region below the plane that was perpendicular to the jet impacting direction were conducted (as shown in Figure 2).

4.2.1. Maximum Radial Sizes $L_{1}$. For the statistics of the cavity sizes in this study are only limited to the region below the initial water surface in the median plane $(Y=0.15 \mathrm{~m})$, the maximum radial size of the cavity occurred at the initial water surface at all times for $\theta_{0}=90^{\circ}$. For $\theta_{0}=45^{\circ}$ and $\theta_{0}=60^{\circ}$, as shown in Figure 10 , the left point $\left(P_{L}\right)$ which determine the maximum radial distance are all located on the initial free surface for inclined jets, but the right point $\left(P_{R}\right)$ are variable. In this study, the maximum radial size considers the maximum radial distance of the left and right cavities in the median plane $(Y=0.15 \mathrm{~m})$.

The normalized radial size $L_{1} / D$ of the cavity versus time is shown in Figure 11. Due to the limitation of mesh resolution, when the changing rate of cavity radial size was small, the points representing the size were stepped, which was particularly obvious when $\theta_{0}=90^{\circ}$. It can be seen from Figure 11, except for $\theta_{0}=45^{\circ}, V_{\text {in }}=2.5 \mathrm{~m} / \mathrm{s}$, the maximum radial size increased with time after impact, and the rate of increase gradually decreased before the cavity pinch-off.

At the same $\theta_{0}$, as the jet velocity increased, the impact velocity increased, the impact angle decreased, and the maximum radial size also increased. Compared with the vertical jet, the maximum radial size of the inclined jets was more affected by the velocity.

Under the same inlet velocity, the maximum radial size for $\theta_{0}=90^{\circ}$ was much larger than $\theta_{0}=45^{\circ}$ and $\theta_{0}=60^{\circ}$. When $\theta_{0}=90^{\circ}$, the jet direction is the same as the direction of gravity, and the cavity is less squeezed by the surrounding water. When $\theta_{0}=45^{\circ}$ and $\theta_{0}=60^{\circ}$, the jet direction is at a certain angle with the direction of gravity, and the squeeze effect to the cavity caused by the surrounding water is significantly enlarged. Since $L_{1}$ for $\theta_{0}=90^{\circ}$ is larger than the one for $\theta_{0}=45^{\circ}$ and $\theta_{0}=60^{\circ}$. For $\theta_{0}=45^{\circ}$ and $\theta_{0}=60^{\circ}$, the differences of $L_{1}$ between them are small at the same inlet velocity. Taking $V_{\text {in }}=2.5 \mathrm{~m} / \mathrm{s}$, for example (Figure 12 ), the trends of the radial size of the left cavity $\left(L_{1 L}\right)$ and the right cavity $\left(L_{1 R}\right)$ are different. $L_{1 L}$ increases as $t V_{j} / D$ increases. $L_{1 R}$ first increases with $t V_{j} / D$, and then decreases due to squeezing until it is pinched off. It can be seen from Figure 12 that there are obvious differences for $L_{1 L}$ and $L_{1 R}$ between $\theta_{0}=45^{\circ}$ and $\theta_{0}=60^{\circ} . L_{1 L}$ for $\theta_{0}=60^{\circ}$ is greater than the one for $\theta_{0}=45^{\circ}$ when $t V_{j} / D$ is small (about less than 6) and $L_{1 L}$ for $\theta_{0}=60^{\circ}$ is less than the one for $\theta_{0}=45^{\circ}$ when $t V_{j} /$ $D>6$. However, it is converse for $L_{1 R}$. At the same $t V_{j} / D$, the difference for $L_{1 L}$ between $\theta_{0}=45^{\circ}$ and $\theta_{0}=60^{\circ}$ is close to the one for $L_{1 R}$, and the value is opposite, so the difference for the sum of $L_{1 L}$ and $L_{1 R}\left(L_{1}=L_{1 L}+L_{1 R}\right)$ is small between $\theta_{0}=45^{\circ}$ and $\theta_{0}=60^{\circ}$. When $V_{\text {in }}=1.5 \mathrm{~m} / \mathrm{s}$ or $2 \mathrm{~m} / \mathrm{s}$, the difference for $L_{1}$ between $\theta_{0}=45^{\circ}$ and $\theta_{0}=60^{\circ}$ is greater (as shown in Figure 11).

4.2.2. Maximum Axial Sizes $L_{2}$. The maximum axial size of the cavity was the maximum length along the jet axis at each time after impact. It can be seen from Figure 9 that for the vertical jets, the jet axis direction was vertical to the water surface; for the inclined jets, the jet axis direction changed, and the smaller the velocity was, the greater the change was. However, the time from the jet impact to the cavity pinch-off was short, and the axial direction of the jet changed little as a whole.

The normalized axial size $L_{2} / D$ of the cavity versus time is shown in Figure 13. Before the cavity pinch-off, the maximum axial size was approximately linear with $t V_{j} / D$, indicating that from the jet impact to the cavity pinch-off, the maximum axial size of the cavity is closely related to the jet impact velocity, but it is not greatly affected by the inclined angle. The ratio $(\lambda)$ of the average axial velocity of the cavity tip $\left(V_{i}\right)$ before cavity pinch-off and the jet impact velocity $\left(V_{j}\right)$ was obtained through the linear fitting method, as shown in Table 6. It can be seen from Table 6 that $\lambda$ was close to 0.5 ; i.e., the axial velocity of the cavity tip after impact was approximately half of the jet impact velocity, which was in accordance with previous views. For vertical circular jets, $\lambda$ ranged between 0.5 and 0.61 in Zhu et al. [5] and 0.443 and 0.872 in Soh et al. [6]. For inclined circular jets, Deshpande and Trujillo [22] also believed that $\lambda$ was approximately equal to 0.5 .

However, the pinch-off time of the cavity was different for different cases, so the maximum axial size of the cavity mainly depended on the impact velocity and pinch-off time and was proportional to the impact velocity and pinch-off time.

\subsection{The Formula of Cavity Size Based on Nonlinear} Regression. In this study, the regression analysis method was used to predict the cavity sizes. The regression analysis method establishes a regression function between the dependent variables and the independent variables using mathematical statistical methods on the basis of mastering a large amount of data. The selected variables should be able to express the problem to be solved. Unnecessary forecasting factors in the model will complicate the description of the process and may lead to poor predictions while ignoring important factors that may reduce the predictive power. The cavity size is mainly affected by the shape and size of the jet angle, velocity, and liquid characteristics. When the water temperature was constant, the variables of time, inclined angle, and velocity of the jet were empirically chosen based on the physical phenomenon. 


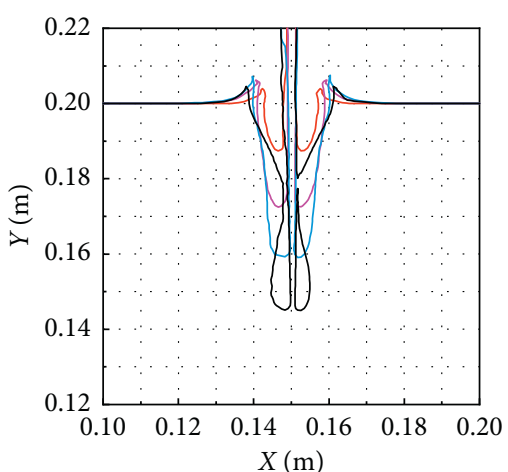

(a)

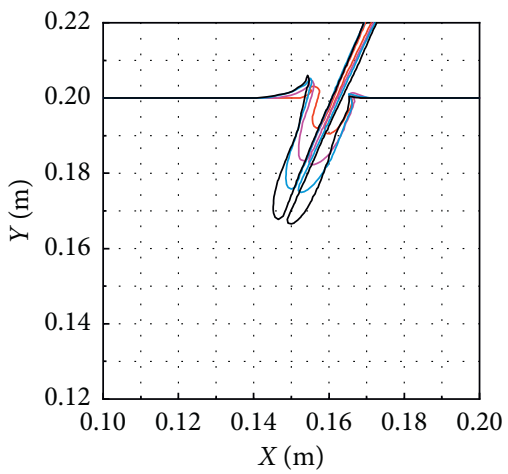

(d)

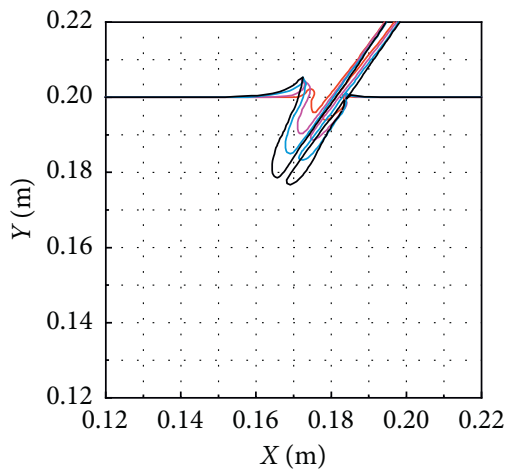

(g)

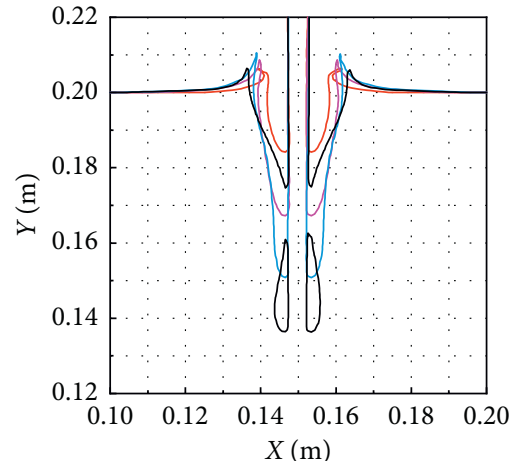

(b)

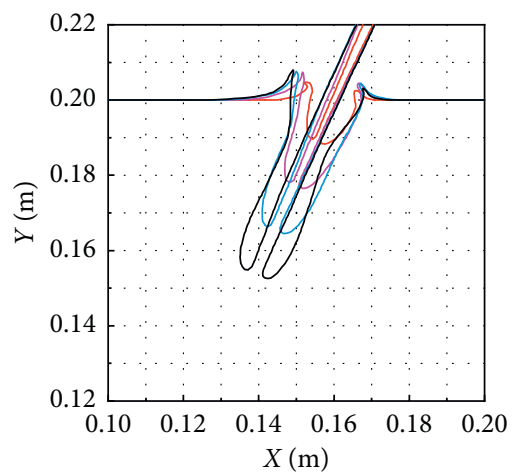

(e)

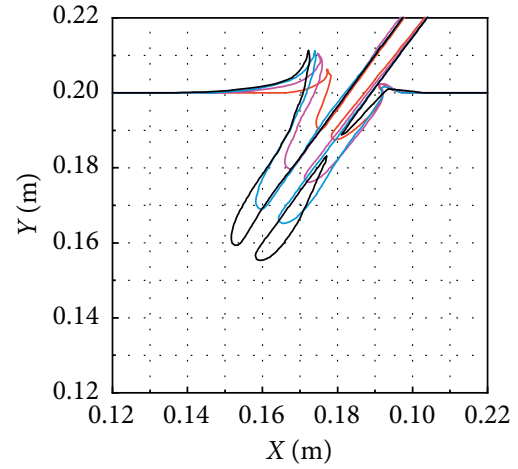

(h)

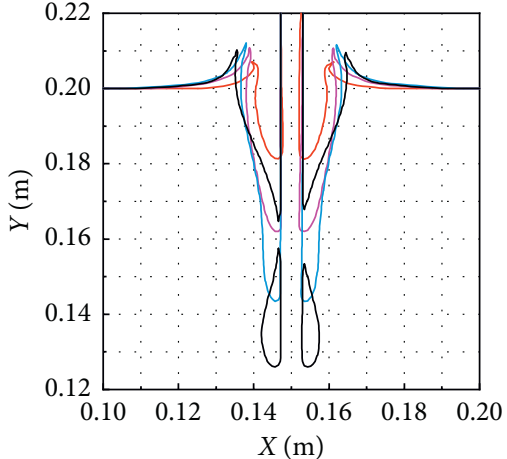

(c)

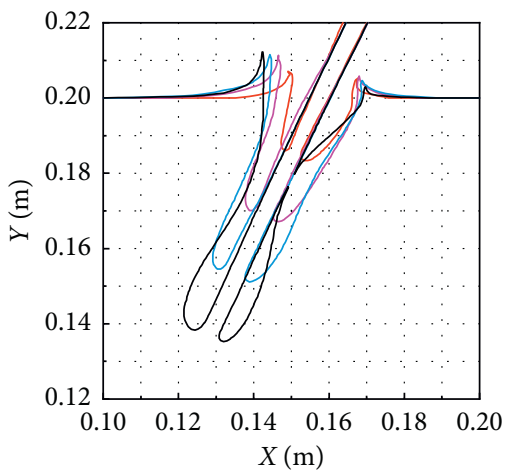

(f)

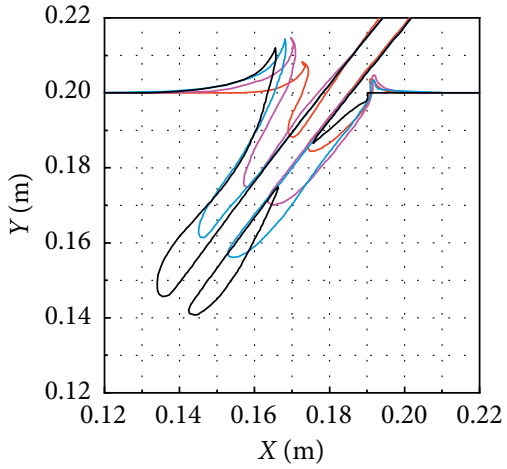

(i)

Figure 9: Cavity temporal evolution in the median plane (the contours are given at four times: $t=1 / 4 t_{p}, 1 / 2 t_{p}, 3 / 4 t_{p}$ and $t_{p} ; Y=0.15 \mathrm{~m}$. (a) Case A1 $\left(\theta_{0}=90^{\circ}, V_{\text {in }}=1.5 \mathrm{~m} / \mathrm{s}\right)$. (b) Case A2 $\left(\theta_{0}=90^{\circ}, V_{\text {in }}=2.0 \mathrm{~m} / \mathrm{s}\right)$. (c) Case A3 $\left(\theta_{0}=90^{\circ}, V_{\text {in }}=2.5 \mathrm{~m} / \mathrm{s}\right)$. (d) Case B1 $\left(\theta_{0}=60^{\circ}, V_{\text {in }}=1.5 \mathrm{~m} /\right.$ s). (e) Case B2 $\left(\theta_{0}=60^{\circ}, V_{\text {in }}=2.0 \mathrm{~m} / \mathrm{s}\right)$. (f) Case B3 $\left(\theta_{0}=60^{\circ}, V_{\text {in }}=2.5 \mathrm{~m} / \mathrm{s}\right)$. (g) Case C1 $\left(\theta_{0}=45^{\circ}, V_{\text {in }}=1.5 \mathrm{~m} / \mathrm{s}\right)$. (h) Case C2 $\left(\theta_{0}=45^{\circ}\right.$, $\left.V_{\text {in }}=2.0 \mathrm{~m} / \mathrm{s}\right)$. (i) Case C3 $\left(\theta_{0}=45^{\circ}, V_{\text {in }}=2.5 \mathrm{~m} / \mathrm{s}\right)$.

The data used to fit and evaluate the models were obtained from CFD to determine the maximum radial and axial sizes of the cavity. Nine cases were evaluated under three jet angles $\left(\theta_{0}\right)$ and three velocities $\left(V_{\text {in }}\right)$, resulting in a data set with 411 records. The nonlinear curve fitting method was used to solve and adjust coefficients. The model performances were assessed by two statistical indicators: the coefficient of determination $\left(R^{2}\right)$ and the root mean square error (RMSE). $R^{2}$ and RMSE are two common indices used to measure the accuracy of a model, which quantifies the difference between the calculated value and the predicted value and makes it possible to compare the performances of models.

$$
\begin{aligned}
R^{2} & =\frac{\sum_{i=1}^{n}\left(L_{e i}-\bar{L}_{s}\right)^{2}}{\sum_{i=1}^{n}\left(L_{s i}-\bar{L}_{s}\right)^{2}}, \\
\text { RMSE } & =\sqrt{\frac{1}{n} \sum_{i=1}^{n}\left(L_{s i}-L_{e i}\right)^{2}},
\end{aligned}
$$

where $L_{e i}$ is the estimated value, $L_{s i}$ is the simulated value, $\overline{L_{s}}$ is the average value of the simulated value, and $n$ is the number of samples. 

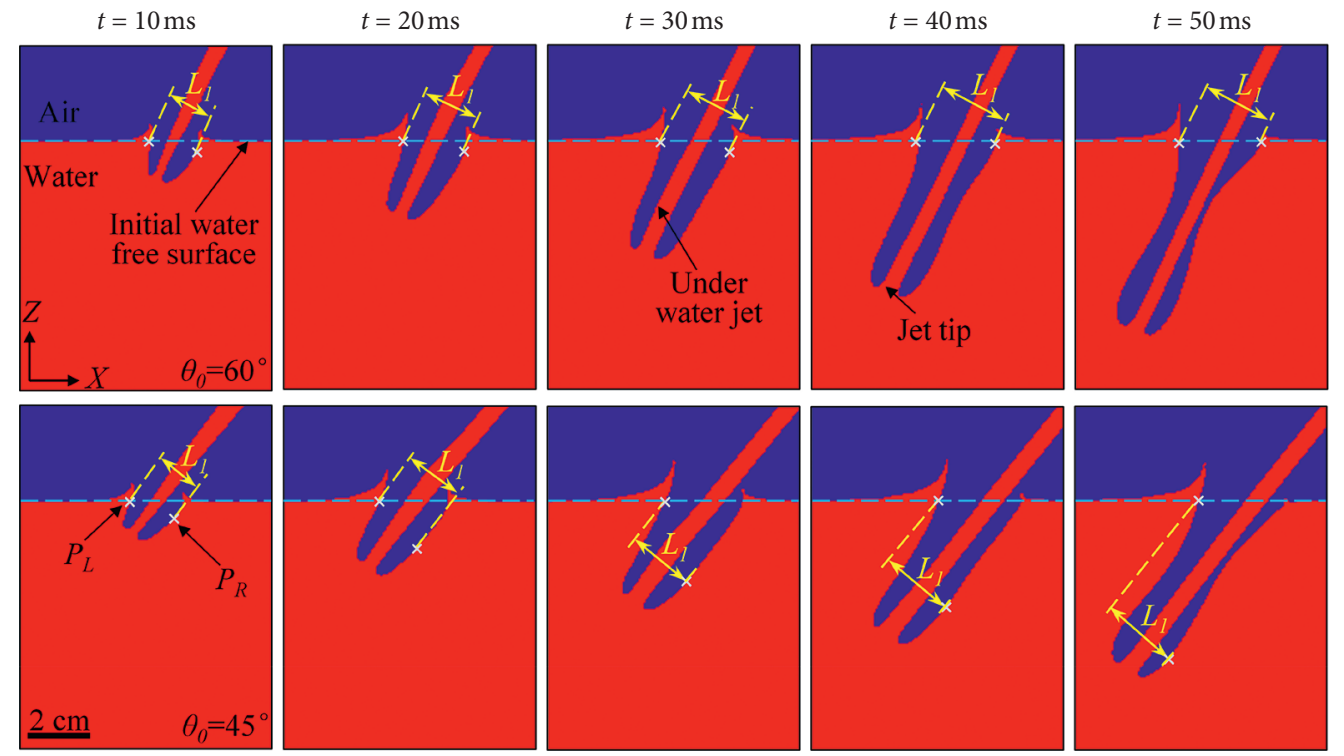

Figure 10: The measurement of $L_{1}$ for $\theta_{0}=60^{\circ}$ and $\theta_{0}=45^{\circ}\left(V_{\text {in }}=2.5 \mathrm{~m} / \mathrm{s}, Y=0.15 \mathrm{~m}\right)$.

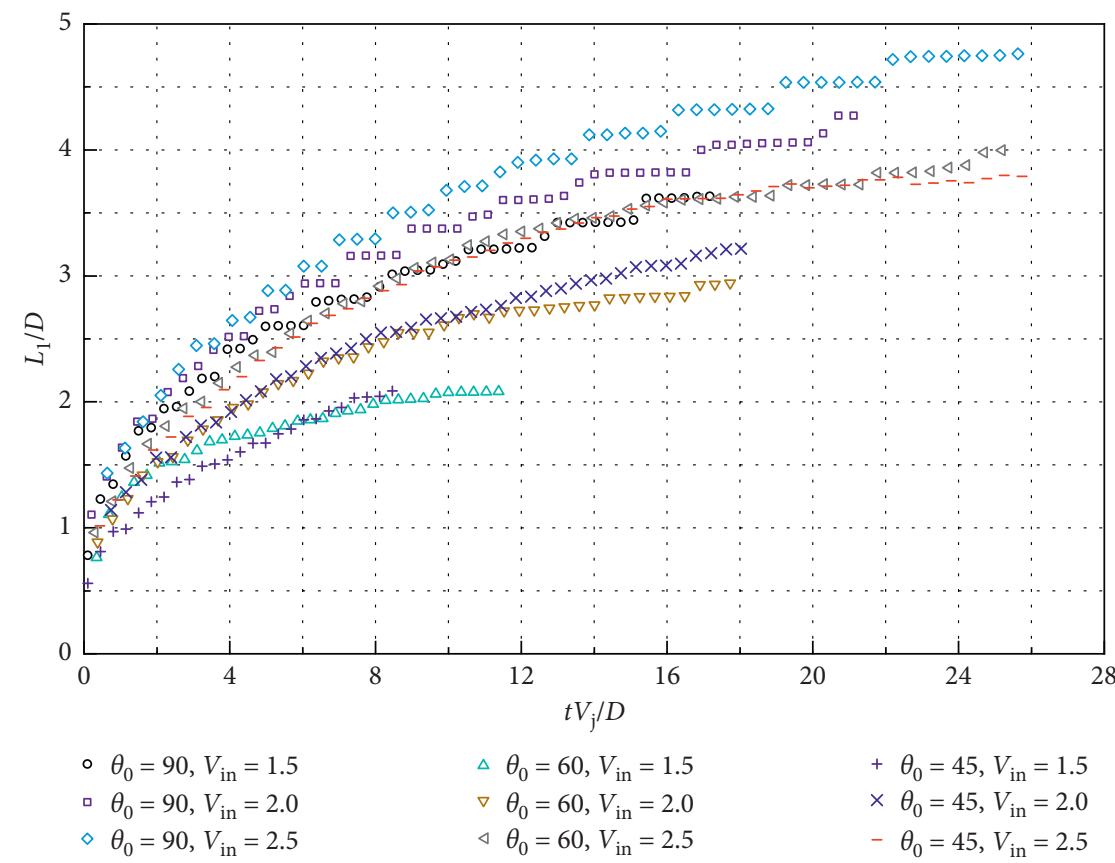

FIgURE 11: Normalized radial size $L_{1} / D$ of the cavity versus time (the unit of $\theta_{0}$ is "o” and the unit of $V_{\text {in }}$ is "m/s").

It can be seen from Figure 11 that when $\theta_{0}=45^{\circ}$ and $\theta_{0}=60^{\circ}$, the radial sizes of the two were relatively close at the same speed, and the difference was larger when compared with $\theta_{0}=90^{\circ}$. Due to the large difference in the variation of $L_{1 R}$ between the inclined jet and the vertical jet, the equation of $L_{1}$ for $\theta_{0}=90^{\circ}$ is different from the one for $\theta_{0}=45^{\circ}$ and $\theta_{0}=60^{\circ}$. Assuming that the physical properties of water are constant, the equation of the maximum radial size $\left(L_{1}\right)$ at different times $(t)$ is

$$
\frac{L_{1}}{D}= \begin{cases}0.13\left(\frac{t V_{j}}{D}\right)^{0.3}\left(\frac{t}{t_{p}}\right)^{0.02}\left(\mathrm{Fr}_{j}\right)^{0.5}\left(\cos \theta_{j}\right)^{-0.003}, & \left(\theta_{0}=45^{\circ}, 60^{\circ}\right), \\ 0.63\left(\frac{t V_{j}}{D}\right)^{-0.08}\left(\frac{t}{t_{p}}\right)^{0.39}\left(\mathrm{Fr}_{j}\right)^{0.46}, & \left(\theta_{0}=90^{\circ}\right),\end{cases}
$$

where $D$ is the diameter of a round nozzle, $V_{j}$ is the impact velocity, $t_{p}$ is the pinch-off time for a cavity, $\theta_{0}$ and $\theta_{j}$ are the 


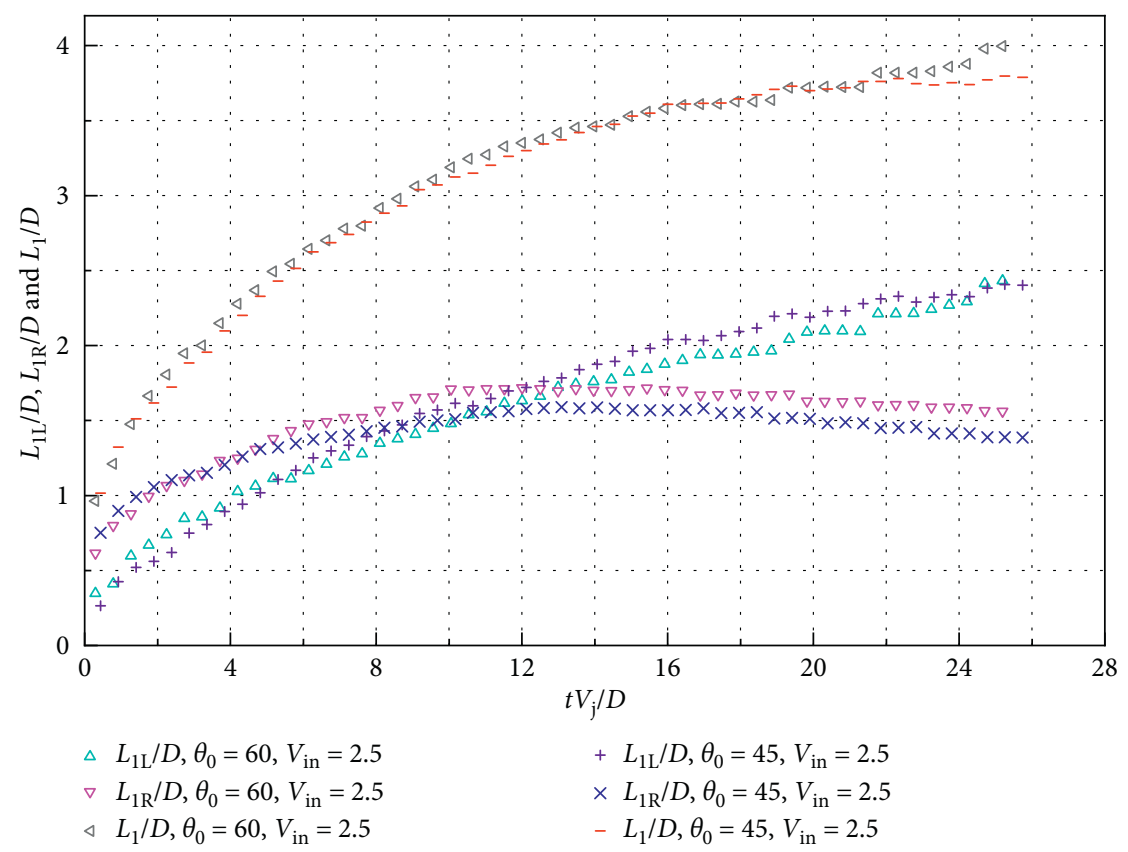

Figure 12: Normalized radial sizes $\left(L_{1 L} / D, L_{1 R} / D\right.$, and $\left.L_{1} / D\right)$ of the cavity versus time (the unit of $\theta_{0}$ is “»” and the unit of $V_{\text {in }}$ is " $\mathrm{m} / \mathrm{s}$ ").

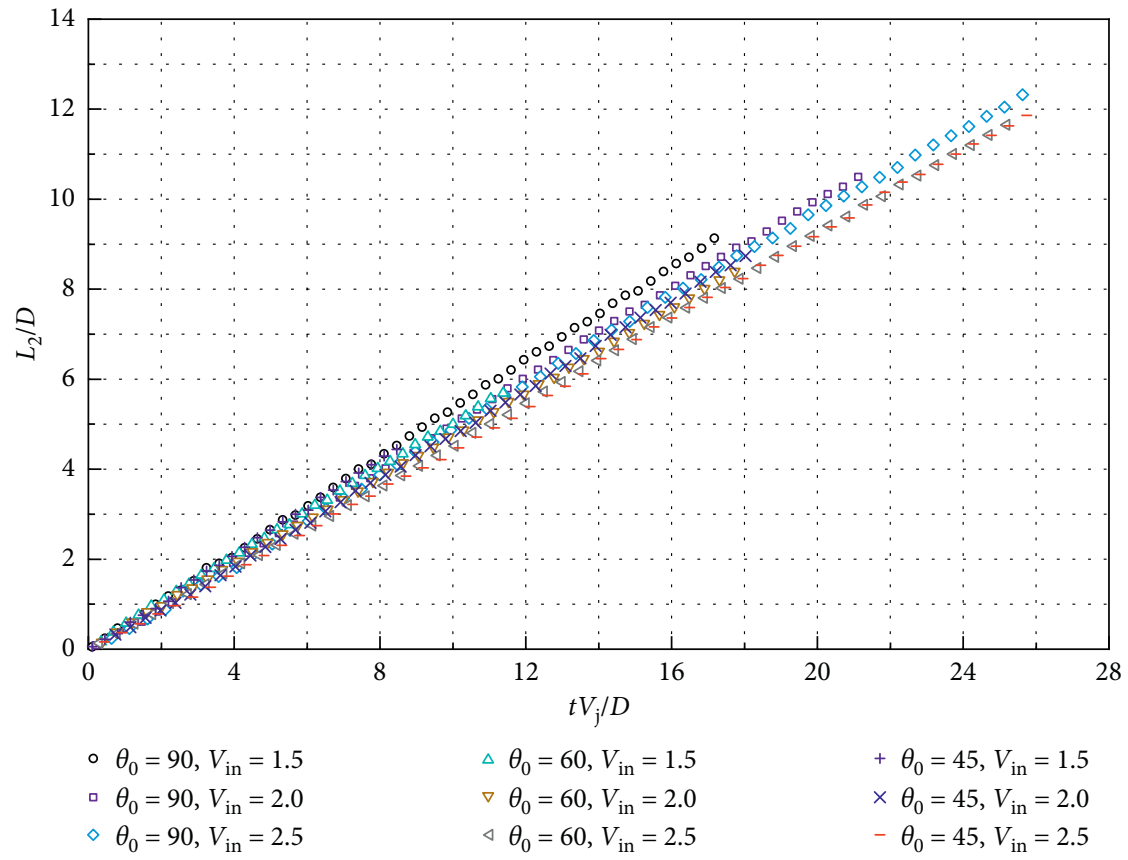

FIGURE 13: Normalized axial size $L_{2} / D$ of the cavity versus time (the unit of $\theta_{0}$ is “”” and the unit of $V_{\text {in }}$ is " $\mathrm{m} / \mathrm{s}$ ").

TABLE 6: The ratio $(\lambda)$ of the average axial velocity of the cavity tip and the jet impact velocity before the cavity pinch-off.

\begin{tabular}{lccccccccc}
\hline Cases & A1 & A2 & A3 & B1 & B2 & B3 & C1 & C2 & C3 \\
\hline$\lambda$ & 0.532 & 0.506 & 0.487 & 0.491 & 0.471 & 0.466 & 0.543 & 0.492 & 0.469 \\
\hline
\end{tabular}




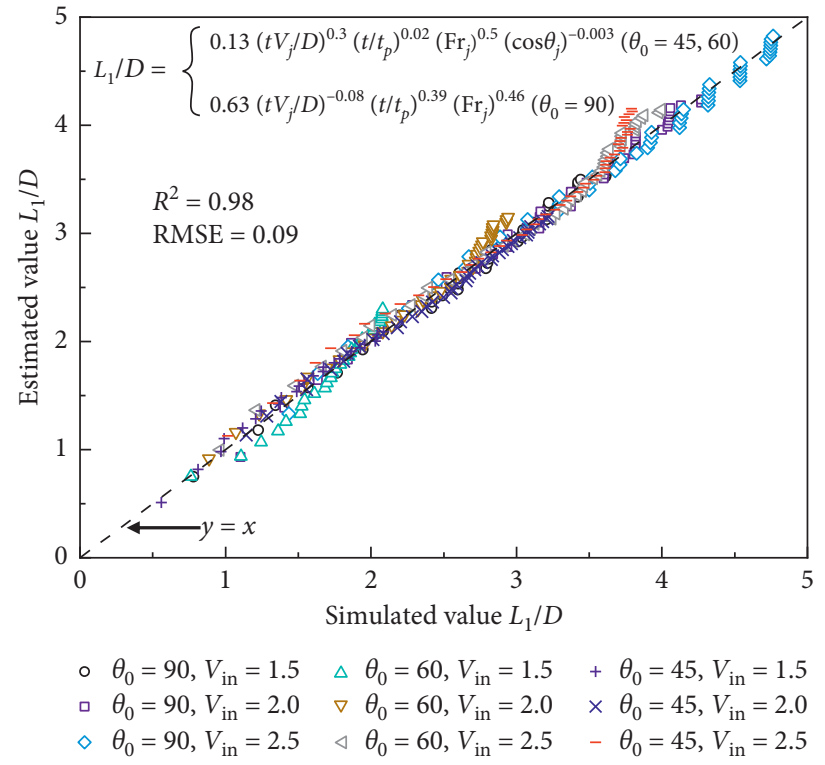

(a)

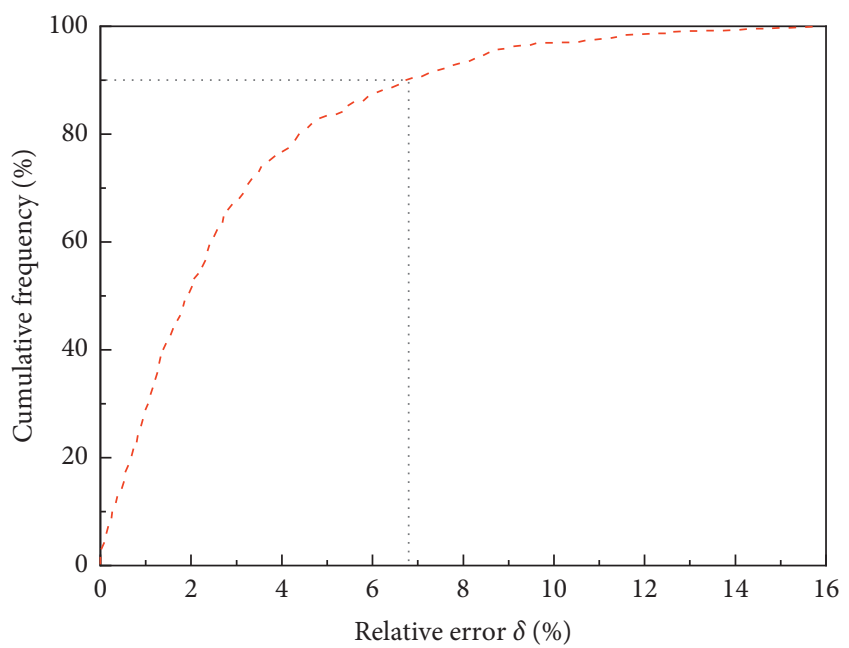

(b)

FIGURE 14: Nonlinear regression: (a) simulated versus estimated values of $L_{1} / D$ (the unit of $\theta_{0}$ is “o” and the unit of $V_{\text {in }}$ is " $\mathrm{m} / \mathrm{s}$ "); and (b) graphical error analysis presenting relative errors $(\delta)$ versus frequency of errors in predictions of $L_{1} / D[(\delta=\mid \operatorname{simulated}-$ estimated $\mid /$ observed $\times 100 \%]$.

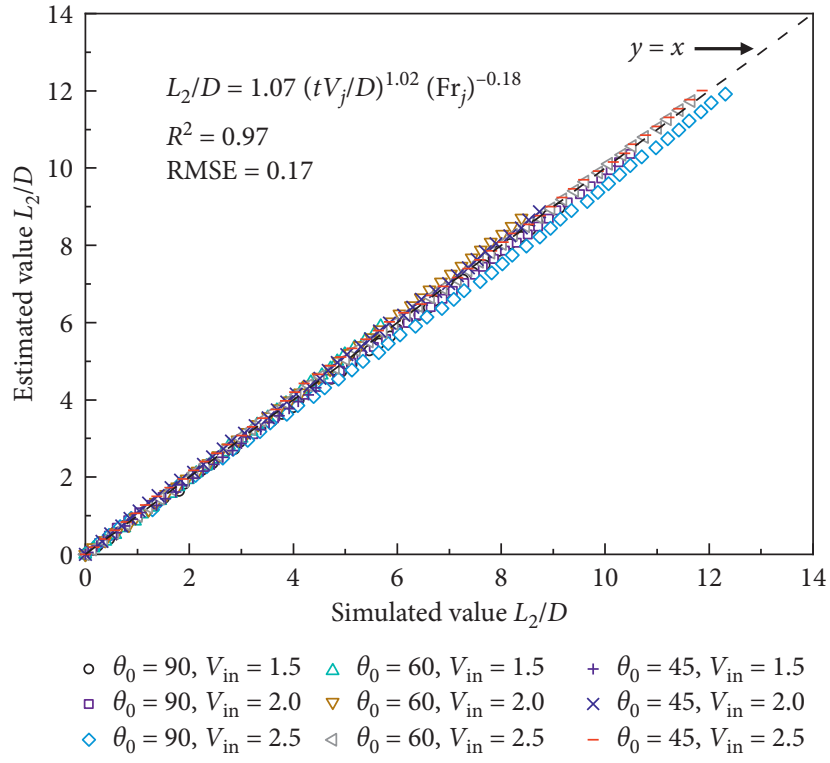

(a)

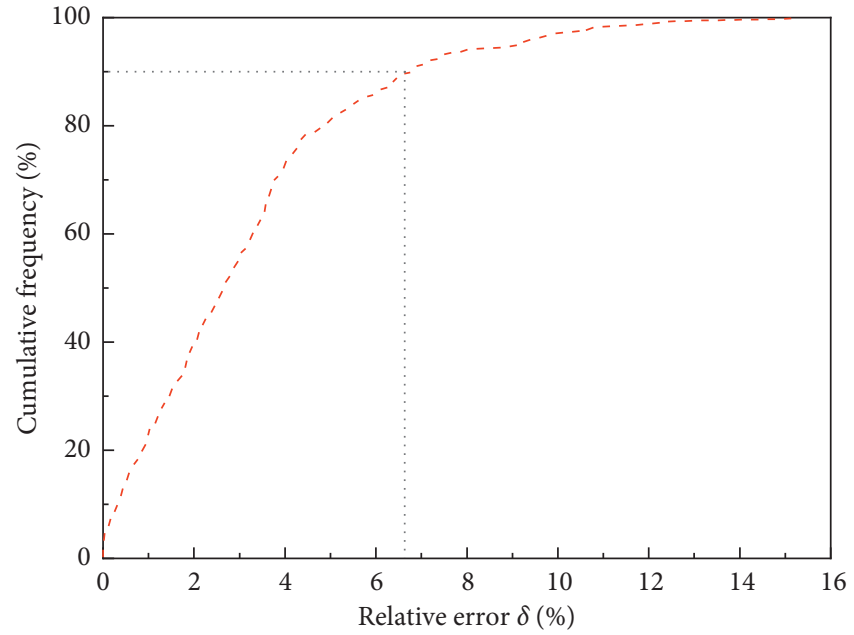

(b)

FIGURE 15: Nonlinear regression: (a) simulated versus estimated values of $L_{2} / D$ (the unit of $\theta_{0}$ is “" " and the unit of $V_{\text {in }}$ is " $\mathrm{m} / \mathrm{s}$ "); and (b) graphical error analysis presenting relative errors $(\delta)$ versus frequency of errors in predictions of $L_{2} / D[(\delta=\mid$ simulated-estimated $\mid /$ observed $\times 100 \%]$.

nozzle inclined angle and jet impact angle $\left(\theta_{j}\right)$ respectively, $\mathrm{Fr}_{j}$ is the Froude number under the impact condition, $\operatorname{Fr}_{j}=\left(V_{j}^{2} / g D\right)$. In equation (6), $0 \leq t \leq t_{p}, 45^{\circ} \leq \theta_{0} \leq 90^{\circ}$, and $70 \leq \mathrm{Fr}_{j} \leq 150$.

To evaluate the accuracy of the prediction equation, the linearity between the simulated and estimated values of radial size is plotted in Figure 14(a). The results showed that $R^{2}$ and RMSE were 0.98 and 0.09 , respectively. The maximum relative error $(\delta)$ of the predicted radial size was $15.9 \%$ (Figure 14(b)). In addition, 90\% of the predictions had $\delta$ values lower than $6.7 \%$. These results proved that equation (6) was suitable for the radial size of the cavity. 
According to Figure 13, the axial size of the cavity was mainly related to time and impact velocity. The relationship between the maximum radial size and the water jet entrance time and impact velocity (equation (7)) is obtained as follows:

$$
\frac{L_{2}}{D}=1.07\left(\frac{t V_{j}}{D}\right)^{1.02}\left(\mathrm{Fr}_{j}\right)^{-0.18}
$$

In equation (7), $0 \leq t \leq t_{p}, \quad 45^{\circ} \leq \theta_{0} \leq 90^{\circ}$, and $70 \leq \mathrm{Fr}_{j} \leq 150$.

Similarly, the linearity between the simulated and estimated values of axial size is plotted in Figure 15(a). The $R^{2}$ and RMSE were 0.97 and 0.17 , respectively. The maximum relative error $(\delta)$ of the predicted axial size was $15.2 \%$ (Figure 15(b)). In addition, $90 \%$ of the predictions had $\delta$ values lower than $6.8 \%$. These results proved the suitable fitting of the mathematical model proposed in equation (7) for axial size.

\section{Conclusions}

In this study, circular water jets plunging into a quiescent pool were simulated by a numerical method. A comparison showed that the simulated results were in good agreement with the experimental values. According to numerical results, this study analyzed the variation of the cavity characteristics at different jet inclination angles and velocities and predicted the cavity size. The results show the following:

(1) The shape of the cavity was mainly affected by the impact angle, while the impact velocity mainly affected the size. The cavity shape was almost symmetrical for vertical jets, but for inclined jets, it was asymmetrical. The pinch-off of the cavity was affected by the secondary water flow. The pinch-off usually starts at a point and expands to different directions until the cavity completely pinches off. The cavity in the opposite direction of flow is pinched off before the cavity in the direction of flow for inclined jets.

(2) Before cavity pinch-off, both the maximum radial and axial size increased with the water jet entrance time and impacted velocity generally. The maximum radial size for $\theta_{0}=90^{\circ}$ was much larger than $\theta_{0}=45^{\circ}$ and $\theta_{0}=60^{\circ}$. For $\theta_{0}=45^{\circ}$ and $\theta_{0}=60^{\circ}$, the differences between them were small. The maximum axial size of the cavity was proportional to the impact velocity and the water jet entrance time. The axial velocity of the cavity tip after impact was approximately half of the jet impact velocity, which was consistent with the views of Zhu et al. [5], Soh et al. [6], and Deshpande and Trujillo [22].

(3) Based on the numerically simulated results, the regression equations of the maximum radial and axial sizes of the cavity were obtained in this study. The equations are applicable when $0 \leq t \leq t_{p}$, $45^{\circ} \leq \theta_{0} \leq 90^{\circ}$, and $70 \leq \mathrm{Fr}_{j} \leq 150$. The regression equations have certain reference significance for predicting the variation of the cavity sizes caused by circular plunging jets before cavity pinch-off.

\section{Data Availability}

The data used to support the findings of this study are included in the article.

\section{Conflicts of Interest}

The authors declare no conflicts of interest.

\section{Acknowledgments}

This work was supported by the China National key R\&D Plan (Grant no. 2016YFC0402006) and the National Natural Science Foundation of China (Grant no. 51979183).

\section{References}

[1] F. H. Harlow and J. P. Shannon, "The splash of a liquid drop," Journal of Applied Physics, vol. 38, no. 10, pp. 3855-3866, 1967.

[2] W. C. Macklin and G. J. Metaxas, "Splashing of drops on liquid layers," Journal of Applied Physics, vol. 47, no. 9, pp. 3963-3970, 1976.

[3] H. N. Og̃uz, A. Prosperettia, and A. R. Kolainia, "Air entrapment by a falling water mass," Journal of Fluid Mechanics, vol. 294, pp. 181-207, 1995.

[4] A. Prosperetti and H. N. Oguz, "Air entrainment upon liquid impact," Philosophical Transactions of the Royal Society of London. Series A: Mathematical, Physical and Engineering Sciences, vol. 355, no. 1724, pp. 491-506, 1997.

[5] Y. Zhu, H. N. Oğuz, and A. Prosperetti, "On the mechanism of air entrainment by liquid jets at a free surface," Journal of Fluid Mechanics, vol. 404, pp. 151-177, 2000.

[6] W. K. Soh, B. C. Khoo, and W. Y. D. Yuen, "The entrainment of air by water jet impinging on a free surface," Experiments in Fluids, vol. 39, no. 3, pp. 498-506, 2005.

[7] H. Chanson, S. Aoki, and A. Hoque, "Physical modelling and similitude of air bubble entrainment at vertical circular plunging jets," Chemical Engineering Science, vol. 59, no. 4, pp. 747-758, 2004.

[8] R. Gómez-Ledesma, K. T. Kiger, and J. H. Duncan, "The impact of a translating plunging jet on a pool of the same liquid," Journal of Fluid Mechanics, vol. 680, pp. 5-30, 2011.

[9] S. S. Deshpande, M. F. Trujillo, X. Wu, and G. Chahine, "Computational and experimental characterization of a liquid jet plunging into a quiescent pool at shallow inclination," International Journal of Heat and Fluid Flow, vol. 34, pp. 1-14, 2012.

[10] X. Qu, A. Goharzadeh, L. Khezzar, and A. Molki, "Experimental characterization of air-entrainment in a plunging jet," Experimental Thermal and Fluid Science, vol. 44, pp. 51-61, 2013.

[11] F. Bonetto and R. T. Lahey, "An experimental study on air carryunder due to a plunging liquid jet," International Journal of Multiphase Flow, vol. 19, no. 2, pp. 281-294, 1993.

[12] M. EI Hammoumi, J. L. Achard, and L. Davoust, "Measurements of air entrainment by vertical plunging liquid jets," Experiments in Fluids, vol. 32, no. 6, pp. 624-638, 2002.

[13] K. Harby, S. Chiva, and J. L. Muñoz-Cobo, "An experimental study on bubble entrainment and flow characteristics of 
vertical plunging water jets," Experimental Thermal and Fluid Science, vol. 57, pp. 207-220, 2014.

[14] S. Miwa, T. Moribe, K. Tsutstumi, and T. Hibiki, "Experimental investigation of air entrainment by vertical plunging liquid jet," Chemical Engineering Science, vol. 181, pp. 251263, 2018.

[15] S. H. Hassan, T. Q. Guo, and P. P. Vlachos, "Flow field evolution and entrainment in a free surface plunging jet," Physical Review Fluids, vol. 4, no. 10, p. 104603, 2019.

[16] G. Guyot, A. Cartellier, and J.-P. Matas, "Depth of penetration of bubbles entrained by an oscillated plunging water jet," Chemical Engineering Science: X, vol. 2, p. 100017, 2019.

[17] A. Y. Galimov, O. Sahni, R. T. Lahey, M. S. Shephard, D. A. Drew, and K. E. Jansen, "Parallel adaptive simulation of a plunging liquid jet," Acta Mathematica Scientia, vol. 30, no. 2, pp. 522-538, 2010.

[18] F. Zidouni Kendil, E. Krepper, A. Bousbia Salah, D. Lucas, and A. Mataoui, "Numerical study of a bubble plume generated by bubble entrainment from an impinging jet," Nuclear Engineering and Design, vol. 241, no. 10, pp. 4111-4121, 2011.

[19] X. L. Qu, L. Khezzar, D. Danciu, M. Labois, and D. Lakehal, "Characterization of plunging liquid jets: a combined experimental and numerical investigation," International Journal of Multiphase Flow, vol. 37, no. 7, pp. 722-731, 2011.

[20] L. Khezzar, N. Kharoua, and K. T. Kiger, "Large eddy simulation of rough and smooth liquid plunging jet processes," Progress in Nuclear Energy, vol. 85, pp. 140-155, 2015.

[21] D. Brouilliot and P. Lubin, "Numerical simulations of air entrainment in a plunging jet of liquid," Journal of Fluids and Structures, vol. 43, pp. 428-440, 2013.

[22] S. S. Deshpande and M. F. Trujillo, "Distinguishing features of shallow angle plunging jets," Physics of Fluids, vol. 25, no. 8, p. 82103, 2013.

[23] J. Ma, A. A. Oberai, D. A. Drew, and R. T. Lahey, "A two-way coupled polydispersed two-fluid model for the simulation of air entrainment beneath a plunging liquid jet," Journal of Fluids Engineering, vol. 134, no. 10, p. 101304, 2012.

[24] A. Boualouache, F. Zidouni, and A. Mataoui, "Numerical visualization of plunging water jet using volume of fluid model," Journal of Applied Fluid Mechanics, vol. 11, no. 1, pp. 95-105, 2018.

[25] T. Afrin, A. A. Khan, N. B. Kaye, and F. Y. Testik, "Numerical model for the hydraulic performance of perforated pipe underdrains surrounded by loose aggregate," Journal of Hydraulic Engineering, vol. 142, no. 8, pp. 1-10, 2016.

[26] Z. Yin, Q. Jia, Y. Li, Y. Wang, and D. Yang, "Computational study of a vertical plunging jet into still water," Water, vol. 10, no. 8, p. 989, 2018.

[27] C. W. Hirt and B. D. Nichols, "Volume of fluid (VOF) method for the dynamics of free boundaries," Journal of Computational Physics, vol. 39, no. 1, pp. 201-225, 1981.

[28] ANSYS Inc., ANSYS Fluent Theory Guide, ANSYS Inc.Canonsburg, PA, USA, 2016. 